\title{
Immediate Postplacental Insertion of Copper Intrauterine Device and Evaluation of Expulsion Rate in Cesarean Section
}

\author{
MANAL M. ABDELLAH, M.D.*; SHAHIENAZ H. EL-SHORBAGY, M.D.*; AMR M. EL-BADRY, M.D.** and \\ NOHA M. HASSAN, M.Sc.* \\ The Departments of Obstetrics \& Gynecology* and Radiology**, Faculty of Medicine, Tanta University, Tanta, Egypt
}

\begin{abstract}
Background: Women who undergo a cesarean section (CS) are in a unique position to receive the intrauterine contraceptive device (IUD). They may also want to use the IUD as a long-acting reversible contraceptive method provided the IUD is safe and effective in the presence of a CS scar.

Aim of Study: We aimed to evaluate the efficacy, displacement and expulsion rates of immediate post placental insertion of IUD.

Patients and Methods: This prospective study was carried out at Obstetrics and Gynecology Department Tanta University Hospital on 60 patients for whom IUD was the chosen contraceptive method.

Results: Mean age among 60 patients included in the present study was 25.10 years, as regard postinsertion complications expulsion in $6 \%$ of patients, endometritis in $8 \%$ and bleeding in $25 \%$, complications occurred after 3 months was in form of expulsion in $2 \%$ of patients, bleeding in $4 \%$ of patients and PID in $2 \%$ and complications occurred after 6 months was in form of expulsion in $4 \%$ of patients bleeding in $5 \%$ of patients, PID in $4 \%$ of patients and pregnancy in $2 \%$ of patients.
\end{abstract}

Conclusion: The findings of the present study confirm previous data that immediate postplacental IUD placement is a viable contraceptive option.

Key Words: Intrauterine device - Postplacental - Cesarean section.

\section{Introduction}

CS rates are rising in all countries, including those of the GS. IUD insertion at the time of CS creates an opportunity to increase access to long-acting reversible contraceptive methods. Conversely, a previous CS scar may deter access to interval insertion of an IUD if a previous CS may result in difficulty with insertion and/or future IUD problems [1].

Correspondence to: Dr. Manal M. Abdellah,

The Department of Obstetrics \& Gynecology, Faculty of Medicine, Tanta University, Tanta, Egypt
Postplacental intrauterine device (IUD) placement, defined as IUD placement within 10min after delivery of the placenta, is an appealing strategy for increasing access to postpartum IUDs because it does not require a separate postpartum visit [2] . Insertion during this period is associated with less discomfort; and puerperal women may have increased motivation for contraception [2] .

\section{Patients and Methods}

This prospective study was carried out at $\mathrm{Ob}-$ stetrics and Gynecology department Tanta University Hospital on 60 patients for whom IUD was the chosen contraceptive method at 2017.

\section{Inclusion criteria:}

Any patients with past history of difficulty in application of IUD post partum due to cervical stenosis. Any patient had contraindication to use other contraceptive method. No anomaly in uterus. single pregnancy.

\section{Exclusion criteria:}

Multiple pregnancies. Placenta previa. Intrapartum fever. Rupture of membrane for longer than 24h. Active untreated lower genital tract infection. Past history of ectopic pregnancy. Any patient with contraindication to use IUD. Patients with recurrent displacement of the loop. Immunocompromised patients, diabetic patients.

All patients were subjected to Full medical history taking, Ultrasonographic examination.

\section{Technique:}

A cooper IUD was placed in the fundus of the uterus within $10 \mathrm{~min}$ of placental delivery (in patients deliver by caesarean section) the IUD was placed through the caesrean section incision using 
a ring forceps and the strings were passed through the cervix, at 6 weeks postpartum the string were trimmed to extend just beyond the external cervical os. During caesrean section all women received prophylactic intravenous cefazon $2 \mathrm{~g}$.

\section{Radiologic testing:}

Prior to discharge, follow-up all patients were re-examined, including abdominal ultrasonography. Transvaginal ultrasonography at 6 weeks, 3 and 6 months postpartum. Patients will instructed to contact one physicians immediately if they experienced pelvic pain, fever, excessive bleeding or an unusual vaginal discharge. Primary outcome: Successful placement, subsequent expulsion.

Secondary outcome: Pregnancy, perforation and other adverse events.

Statistical analyses: Were performed using SPSS software, one way analysis of variance was performed for parametric variables between patients with a normal distribution.

\section{Results}

This prospective cohort study was conducted at Tanta University Hospital on 60 patients for whom IUD was the chosen contraceptive method with the following result:

Mean age among 60 patients included in the present study was 25.10 years with $53.3 \%$ of them $<25$ years and $46.7 \%>25$ years, mean parity was 2.23 , the most of the included patients had secondary school $36.7 \%$ of them as regarding economic status $40 \%$ had low economic status, $36.7 \%$ had medium economic status and $23.3 \%$ had high economic status (Table 1).

$63.3 \%$ of patients had no history of previous IUD use but $36.7 \%$ had previous use of IUD, as regarding future fertility desire $83.3 \%$ of patients desired to fertility (Table 2) $40 \%$ of the patients chose IUD posplacental insertion due to Difficult to return to takes methods, $36.7 \%$ used it due to its History of difficult insertion and $23.3 \%$ used it due to Cervical stenosis (Table 3).

Complications occurred after 6 weeks of insertion was in form of expulsion in $6 \%$ of patients, endometritis in $8 \%$ and bleeding in $25 \%$, complications occurred after 3 months was in form of expulsion in $2 \%$ of patients, bleeding in $4 \%$ of patients and PID in $2 \%$ and complications occurred after 6 months was in form of expulsion in $4 \%$ of patients bleeding in $5 \%$ of patients, PID in $4 \%$ of patients and pregnancy in $2 \%$ of patients (Table 4).
The expulsion rate occurred in $3.3 \%$ of patients within 7 days and on $1.3 \%$ of patients in 7 day-4 weeks. $55 \%$ of them only displacement happened and $45 \%$ totally displacement (Table 5, Figs. 1,2). $75 \%$ of patients having bleeding was in the form of menorrhagia and $25 \%$ in form of metrorrahgia, $75 \%$ of them got bleeding after preperium and $25 \%$ in preperium (Table 6 ), patients who got infection was in the form of endometritis in 4 patients and in preperium in form of PID in 3 patients (Table 7).

Table (1): Distribution of the studied cases according to demographic data $(n=60)$.

\begin{tabular}{|c|c|c|}
\hline & No. & $\%$ \\
\hline \multicolumn{3}{|l|}{ Age (years) } \\
\hline$<25$ & 32 & 53.3 \\
\hline$\geq 25$ & 28 & 46.7 \\
\hline Min.-Max. & \multicolumn{2}{|c|}{$18.0-36.0$} \\
\hline Mean \pm SD. & \multicolumn{2}{|c|}{$25.10 \pm 5.38$} \\
\hline Median & \multicolumn{2}{|c|}{24.0} \\
\hline Min.-Max. & Mean \pm SD. & Median \\
\hline \multirow[t]{2}{*}{ Parity } & $2.23 \pm 0.93$ & 2.0 \\
\hline & No. & $\%$ \\
\hline \multicolumn{3}{|l|}{ Education } \\
\hline No formal education & 6 & 10.0 \\
\hline Primary & 14 & 23.3 \\
\hline Secondary & 22 & 36.7 \\
\hline Higher education & 18 & 30.0 \\
\hline \multicolumn{3}{|l|}{ Economic status: } \\
\hline Low & 24 & 40.0 \\
\hline Medium & 22 & 36.7 \\
\hline
\end{tabular}

Table (2): Distribution of the studied cases according to previous IUD use and future fertility desire $(n=60)$.

\begin{tabular}{lcc}
\hline & No. & $\%$ \\
\hline Previous IUD use: & \\
No & 38 & 63.3 \\
Yes & 22 & 36.7 \\
Future fertility desire: & & \\
No & 10 & 16.7 \\
Yes & 50 & 83.3 \\
\hline
\end{tabular}

Table (3): Distribution of the studied cases according to reasons for acceptability $(n=60)$.

\begin{tabular}{lcc}
\hline & No. & $\%$ \\
\hline Reasons for acceptability: & & \\
$\quad$ Cervical stenosis & 14 & 23.3 \\
Difficult to return to takes methods & 24 & 40.0 \\
History of difficult insertion & 22 & 36.7 \\
\hline
\end{tabular}


Table (4): Distribution of the studied cases according to complications $(n=60)$ after 6 weeks, 3 months and 6 months.

\begin{tabular}{lcccccc}
\hline \multirow{2}{*}{ Complications } & \multicolumn{2}{c}{ After 6 weeks } & \multicolumn{2}{c}{3 months } & \multicolumn{2}{c}{6 months } \\
\cline { 2 - 7 } & No. & $\%$ & No. & $\%$ & No. & $\%$ \\
\hline Expulsion & 4 & 6 & 1 & 2 & 2 & 4 \\
Endometritis & 4 & 8 & 0 & 0 & 0 & 0 \\
bleeding & 15 & 25 & 2 & 4 & 3 & 5 \\
Sub involution of & 0 & 0 & 0 & 0 & 0 & 0.0 \\
$\quad$ uterus & & & & & & \\
\hline PID & 0 & 0 & 1 & 2 & 2 & 4 \\
Pregnancy & 0 & 0 & 0 & 0 & 1 & 2 \\
\hline
\end{tabular}

Table (5): Distribution of the studied cases according to timing and rate of expulsion $(n=7)$.

\begin{tabular}{lll}
\hline & No. & $\%$ \\
\hline Type of expulsion: & & \\
Displacement & 4 & 55 \\
Total expulsion & 3 & 45 \\
Timing and rate of expulsion: & & \\
No & 53 & 92 \\
7 days & 3 & 3.3 \\
7 day - 4 weeks & 1 & 1.3 \\
More than 4 wks & 3 & 3.3 \\
\hline
\end{tabular}

Table (6): Distribution of the studied cases according to bleeding $(\mathrm{n}=20)$.

\begin{tabular}{cll}
\hline & No. & $\%$ \\
\hline Type ofbleeding: & & \\
Menorrhagia & 15 & 75 \\
Metrorrahgia & 5 & 25 \\
Timing ofbleeding: & & \\
In preperium & 15 & 75 \\
After preperium & 5 & 25 \\
\hline
\end{tabular}

Table (7): Distribution of the studied cases according to infection $(\mathrm{n}=7)$.

\begin{tabular}{lll}
\hline & No. & $\%$ \\
\hline Type of infection: & & \\
Endometritis & 4 & 55 \\
PID & 3 & 45 \\
Timing of infection: & & \\
In preperium & 4 & 55 \\
After preperium & 3 & 45 \\
\hline
\end{tabular}

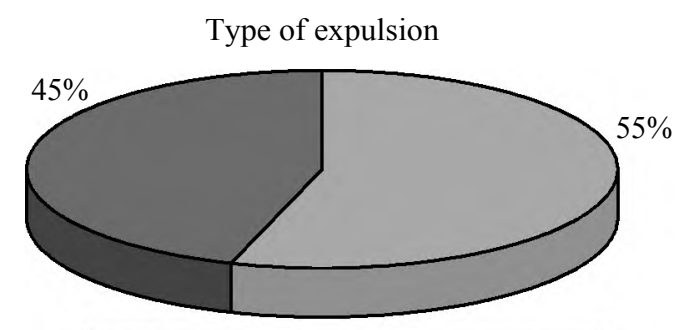

Total expulsion $\square$ Displacement

Fig. (1): Distribution of the studied cases according to type of expulsion.

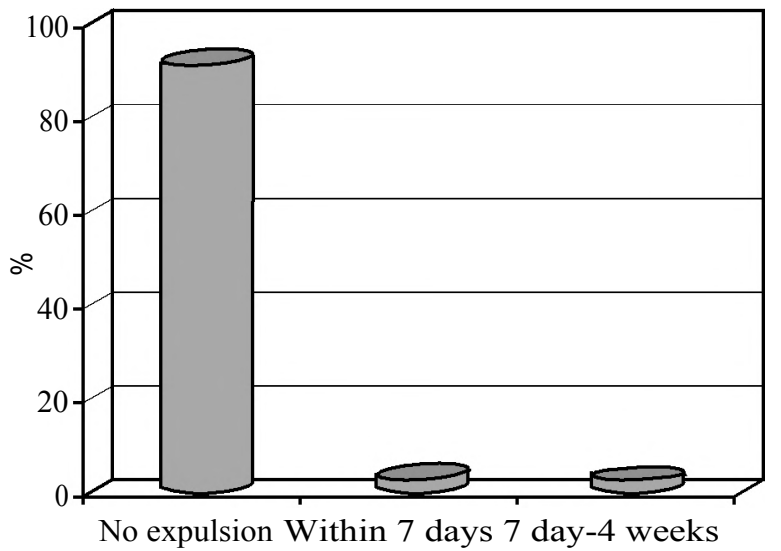

Fig. (2): Distribution of the studied cases according to timing and rate of expulsion.

\section{Discussion}

Immediate postpartum intrauterine device (IUD) insertion deserves great attention as it can provide immediate contraception and prevents repeat unintended pregnancies [3]

In the present study we aimed to evaluate the efficacy, displacement and expulsion rates of immediate post placental insertion of IUD, we include 60 patients for whom IUD was the chosen contraceptive method.

In the present study we found that mean age among 60 patients included in the present study was 25.10 years with $53.3 \%$ of them $<25$ years and $46.7 \%>25$ years. Mean parity was $2.23 .63 .3 \%$ of patients had no history of previous IUD use but $36.7 \%$ had previous use of IUD, as regarding future fertility desire $83.3 \%$ of patients desired to fertility.

Sharma A., et al., found that among total of 113 women were included with $45.13 \%$ of them aged $20-25$ yrs, $43.36 \%$ aged $26-30$ years and $11.50 \%$ aged $31-35$ years $48.67 \%$ of them were para 2 and $7.07 \%$ more than $3[4]$.

Another study by Maluchuru S. et al., they conclude 1000 patients with 558 patients aged 2029 years, 383 aged $30-39$ years and 59 aged $<19$ years, 572 patients were para 1,348 patients were para 2 and 80 patients were para 3,608 patients had last birth since 1-2 years [5].

In the current study $40 \%$ of the patients chose IUD posplacental insertion due to Difficult to return to takes methods, $36.7 \%$ used it due to its History of difficult insertion and $23.3 \%$ used it due to Cervical stenosis.

Compared with other contraceptive methods, early post-partum IUD insertion has several advan- 
tages. It provides immediate contraception without interfering with breast feeding, and it may avoid discomfort related to insertion. Inserting an IUD immediately after placental removal has not been associated with increased infection, uterine perforation, postpartum bleeding, or uterine subinvolution. The expulsion rate is higher (approximately $12 \%$ in the first postpartum year) after immediate postpartum insertion compared to insertion 4 to 8 weeks later. Continuation rates are relatively high (87.6\% and $76.3 \%$, at 6 and 12 months, respectively) [6]

In the present study we found that complications occurred after 6 weeeks of insertion was in form of expulsion in $6 \%$ of patients, endometritis in $8 \%$ and bleeding in $25 \%$, complications occurred after 3 months was in form of expulsion in $2 \%$ of patients, bleeding in $4 \%$ of patients and PID in $2 \%$ and complications occurred after 6 months was in form of expulsion in $4 \%$ of patients bleeding in $5 \%$ of patients, PID in $4 \%$ of patients and pregnancy in $2 \%$ of patients.

The cumulative expulsion rates had a similar frequency of 8.7, 8.9 and $11.3 \%$ in groups 1,2 and 3 , respectively ( $p>0.05$ in all pair wise comparisons). The expulsion rates at 6 weeks postpartum were $4.3,6.7$ and $9.7 \%$ in groups 1,2 and 3, respectively ( $p>0.05$ in all pair wise comparisons). In each group, more than half of the expulsions occurred within 6 weeks postpartum. There were no pregnancies in the study population while the IUD was in place. Suggesting that immediate postplacental insertion of Copper IUD is a safe and effective method [2], which is in accordance with the previous reports [7].

In agreement with our result Welkovic et al., [8] studied post-partum bleeding and infection after post placental IUD insertion and found no difference in the incidence of excessive bleeding.

On the other hand et al., revealed that Immediate post placental insertion (within 10 minutes of delivery of the placenta) of copper-bearing or hormone-releasing IUDs is generally safe and acceptable, although compared with interval insertion it carries a higher risk of expulsion, thus affecting effectiveness and overall patient acceptance.

In the current study we found that $75 \%$ of patients having bleeding was in the form of menorrhagia and $25 \%$ in form of metrorrahgia, $75 \%$ of them got bleeding after preperium and $25 \%$ in preperium, patients who got infection was in the form of endometritis in 4 patients and in preperium in form of PID in 3 patients.

As regard bleeding post insertion a study by Zhang H., et al., the objective was to study the effects of immediate insertion of a frameless IUD during Cesarean section on the bleeding pattern, duration of lochia and healing of uterus. Two hundred women used the IUD and 204 women who did not use the IUD served as the control group. Follow-up visit was performed at 42 days and 90 days after delivery. There was no significant difference in postpartum hemorrhage, continuance of lochia, and healing of uterus was normal.

The expulsion rate was $4 \%$. However, it was found that removal of the IUD was difficult in a significant number of women due to the slow degradation time of the cone material. It was concluded that further research on the improvement of absorption time of the biodegradable component may provide additional benefits of the retention technology.

In a systematic review by Kapp, et al., [10] the outcomes of post-partum insertion of IUD at different time interval were compared. The evidence demonstrated no increase in risk of complications among women who had an IUD inserted during the post-partum period; however, some increase in expulsion rates occurred with delayed postpartum insertion when compared to immediate insertion. Expulsion rates were more when compared to interval insertion. Post-placental insertions during caesarean section were associated with lower expulsion rates than post-placental vaginal insertions without any increase in other complications [5].

\section{Conclusion:}

The findings of the present study confirm previous data that immediate postplacental IUD placement is a viable contraceptive option.

\section{References}

1- GOLDSTUCK N.D. and STEYN P.S.: Insertion of intrauterine devices after cesarean section: A systematic review update. International Journal of Women's Health. 18 April Volume, 2017: 9 Pages, 205-212, 2017.

2- SUCAK A., OZCAN S., ÇELEN Ş., et al.: Immediate postplacental insertion of a copper intrauterine device: A pilot study to evaluate expulsion rate by mode of delivery. BMC Pregnancy and Childbirth, 15: 202, 2015.

3- RODRIGUEZ M.I., EVEN M. and ESPEY E.: Advocating for immediate postpartum LARC: Increasing access, improving outcomes, and decreasing cost. Contraception. 90 (5): 468-471, 2014. 
4- SHARMA A., GUPTA V., BANSAL N., et al.: A prospective study of immediate postpartum intra uterine device insertion in a tertiary level hospital. Int. J. Res. Med. Sci. Jan., 3 (1): 183-187, 2015.

5- MALUCHURU S., ARUNA V. and PRABHAVATHI N. Post Partum $=$ Intrauterine Device Insertion $=2 \mathrm{yr}$ Experience at a Tertiary Care Center in Guntur Medical College /Govt. General Hospital, Guntur. (IOSR-JDMS). Volume 14, Issue 3 Ver. IV, pp 56-61, 2015.

6- ÇELEN Ş., SUCAK A., Y1LD1Z Y., et al.: Immediate postplacental insertion of an intrauterine contraceptive device during cesarean section. Contraception, 84: 2403, 2011 .
7- LARA RICALDE R., MENOCAL TOBIAS G., RAMOS PÉREZ C., et al.: Random comparative study between intrauterine device Multiload Cu375 and TCu 380a inserted in the postpartum period [in Spanish]. Ginecol. Obstet. Mex., 74: 306-11, 2006.

8- STEFAN WELKOVIC, COSTA L., FAUNDES A., et al.: Postpartum bleeding and infection after postplacental IUD insertion. Contraception, 63: 155-8, 2011.

9- ZHANG H., FANG G. and ZHOU C.: Study on GyneFix PP IUD insertion during cesarean section. Chinese Journal of Family Planning, 12 (8): 481-482, 2004.

10- KAPP N. and CURTIS K.M.: Intrauterine device insertion during the postpartum period: A systematic review. Contraception, 80 (4): 327- 336, 2009.

\section{تقييه وضع اللولب النحاسى مباشرة

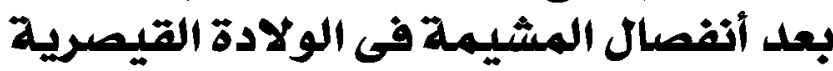

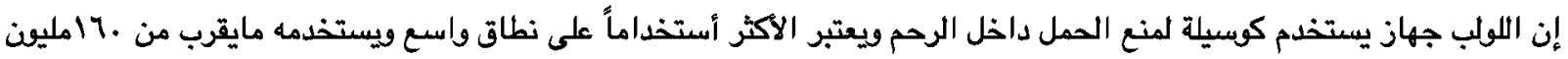

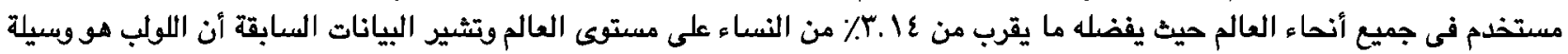
فعالة مثل عملية ربط الأنابيب على الرغم من المضاعفات المعروفة مثل زيادة نزيف الطمث وآلام الطمث.

أستخدام اللولب على الفود بعد ولادة المشيمة أثناء القيصرية فى غضون ـ ادقائق يتميز الإستخدام فى هذه الفترة بتقليل مشقة التركيب

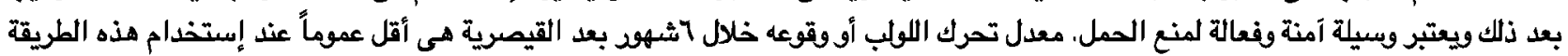

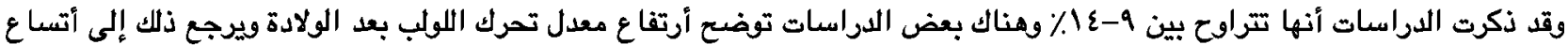
عنق الرحم.

وقد أوضحت بعض الدراسات سلامة هذه الوسيلة منها ما نشر فى الولايات المتحدة من معايير نشرت لإستخدام وسائل منع الحمل المختلفة.

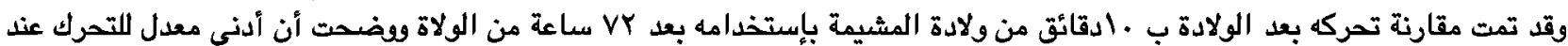

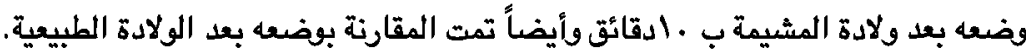

وبذلك يتم التوجيه بإستخدامه فى هذه الفترة بالرغم من المضاعفات التى يمكن أن تحدث فى الأسابيع التالية للولادة مثل أنقاب الرحم

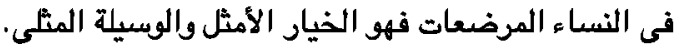

